\title{
ILLUSTRATION OF AMINO ACIDS REACTIONS AND PROTEINS CHARACTERIZATION FOR EXPERIMENTAL BIOCHEMISTRY CLASSES
}

\author{
Parreira, I. and Ciancaglini, $P$. \\ Departamento de Química, Faculdade de Filosofia, Ciências e Letras de Ribeirão \\ Preto, Universidade de São Paulo, Ribeirão Preto, São Paulo, Brazil.
}

New teaching methodologies have been developed to facilitate the learning of biochemistry concepts. A new approach to Biochemistry teaching has become more frequent, one that does not require reagents but use photos, videos, softwares etc. Experimental Biochemistry classes, i.e. covering characterization of amino acids and proteins, might be more productive with the use of complementary didactic material. Furthermore, if experiments cannot be implemented, classes may be well illustrated with complementary didactic material covering from the simplest to the most complex experiments. In order to aid Biochemistry classes without practical experiments, some tests and reactions were documented in our laboratory through digital photos, for instance: (1) the biuret reaction wherein the blue reagent turns violet in the presence of proteins and changes to pink when combined with short-chain polypeptides; (2) the ninhydrin test used in amino acid analysis of proteins: most of the amino acids are hydrolyzed and react with ninhydrin; when reacting with these free amines, a deep blue or purple color appears; (3) methods for detecting proteins wherein spectrophotometry is used, that deals with the relationship between absorbance, concentration and path length, which constitute the Beer-Lambert Law. A didactic material constituted by texts, schemes and illustrated by photos has been created for each class topic. This material can be used either as a teacher script or in a presentation form to illustrate classes without experimental activities.

Financial Support: Pro-Reitoria Graduação-USP, CNPq.

Key words: didactic material, determination reactions, amino acids, proteins, biochemistry classes 